EPSC Abstracts

Vol. 15, EPSC2021-251, 2021

https://doi.org/10.5194/epsc2021-251

Europlanet Science Congress 2021

(C) Author(s) 2021. This work is distributed under

the Creative Commons Attribution 4.0 License.

\title{
Dynamical Phenomena in Martian dust storms
}

Agustin Sanchez-Lavega ${ }^{1}$, Juan Manuel Leyva², Aitor Erkoreka ${ }^{2}$, Josu García-Morales ${ }^{2}$, Jorge Hernández-Bernal ${ }^{1,2}$, Teresa del Rio-Gaztelurrutia ${ }^{1}$, Iñaki Ordoñez-Etxeberria ${ }^{3}$, Alejandro Cardesin ${ }^{4}$, Ricardo Hueso ${ }^{1}$, Dimitri Titov ${ }^{5}$, Simon Wood ${ }^{6}$, Daniela Tirsch 7 , Ernst Hauber ${ }^{7}$, and Klaus-Dieter Matz ${ }^{7}$ ${ }^{1}$ Universidad Pais Vasco UPV/EHU, Escuela de Ingeniería de Bilbao, Física Aplicada I, Bilbao, Spain (agustin.sanchez@ehu.es)

${ }^{2}$ Aula EspaZio Gela, Escuela de Ingeniería de Bilbao, Universidad del País Vasco UPV/EHU, Bilbao, Spain

${ }^{3}$ Planetario de Pamplona, Pamplona, Spain

${ }^{4}$ European Space Agency, ESAC, Madrid, Spain

${ }^{5}$ European Space Agency, ESTEC, Noordwijk, Netherland

${ }^{6}$ European Space Agency, ESOC, Darmstadt, Germany.

${ }^{7}$ German Aeroespace Center (DLR), Institute of Planetary Research, Berlin, Germany

We present a study of the morphology, patterns, and dynamics of dust storms on Mars observed at the edge of the North Polar cap during the Northern Hemisphere Spring Equinox from May to June 2019 (MY35) [1] and of the onset of the Global Dust Storm in May to June 2018 (MY34) [2]. The analysis is based on images obtained by the Visual Monitoring Camera (VMC) [3] and the High Resolution Stereo Camera (HRSC) [4] onboard Mars Express, and MARCI camera onboard Mars Reconnaissance Orbiter (MRO) [5-6]. VMC images were analyzed with tools described in previous works [7-8], HRSC images were analyzed from map-projections, and MARCI were processed and projected using the Integrated Software for Imagers and Spectrometers (ISIS) of the USGS [9].

The dust activity at the edge on the North Polar cap in MY35 ( $\mathrm{Ls}=28^{\circ}-35^{\circ}$ ) took place around latitude $60^{\circ} \mathrm{N}$ in the longitude range $140^{\circ} \mathrm{E}-240^{\circ} \mathrm{E}$ (along Acidalia, Arcadia and Amazonis planitias). These features exhibited a rich phenomenology typical of this season with different morphologies in form of filaments and fronts, flushing storms (large arc-shaped features), compact textured storms and well developed spiral systems, sometimes mixed with water-ice clouds [1]. Here we concentrate in these last two types of features.

The textured and spiral storms are of local type (areas $<1.6 \times 10^{6} \mathrm{~km}^{2}$ )and contained cellular patterns suggestive of organized active updrafts within the storms. The cells varied in size from one storm to other: $50 \times 20 \mathrm{~km}, 135 \times 60 \mathrm{~km}$ and $70 \times 40 \mathrm{~km}$. In all cases, the cell texture is anisotropic in the horizontal size (length/width, $\mathrm{l} / \mathrm{w} \sim 2$ ) with values well above the atmospheric scale height $(\mathrm{H} \sim$ $8 \mathrm{~km}$ ). Measured local winds reached velocities from 20 to $45 \mathrm{~ms}^{-1}$. The presence of storms with such different overall structure, for example in the form of compact areas on the one hand and spiral systems on the other, indicates that the underlying mechanisms are different but that above a threshold velocity, all of them generate the dust storms. We explore the action of dry convection in the formation of these patterns driven by buoyancy generated by the radiative heating of atmospheric dust.

The onset of the last Global Dust Storm (GDS 2018) took place on 30 May $2018\left(\right.$ Ls $=182^{\circ}$ ) at latitude $\sim 33^{\circ} \mathrm{N}$ and longitude $342^{\circ} \mathrm{E}$, following a precursor storm on 26-27 May 2018 at latitude 
$58^{\circ} \mathrm{N}$ and longitude $325^{\circ} \mathrm{E}$ [2]. The MARCI high-resolution images reveal again the presence of cellular patterns at different scales (typically $40 \times 20 \mathrm{~km}$ ) with a well defined frontal line marking the storm advance. The storm morphology rapidly evolved in one day showing patterns of long wave trains with wavelengths ranging from 10 to $20 \mathrm{~km}$. We interpret these as gravity waves formed by intense winds flowing over craters and other topographic structures.

\section{References:}

[1] Sánchez-Lavega A. et al., Patterns in textured dust storms in Mars North Pole, Europlanet Science Congress 2020, EPSC Abstracts Vol., EPSC2020-141 (2020)

[2] Sánchez-Lavega A., T. del Río-Gaztelurrutia, J. Hernández-Bernal,M. Delcroix, The onset and growth of the 2018 Martian Global Dust Storm, Geophys. Res. Lett., 46, 6101-6108 (2019). doi.org/10.1029/2019GL083207.

[3] Ormston, T., Denis, M., Scuka, D., \& Griebel, H., An ordinary camera in an extraordinary location: Outreach with the Mars Webcam. Acta Astronautica, 69, 703-713 (2011)

[4] Jaumann, R., Neukum, G., Behnke, T., Duxbury, T. C., Eichentopf, K., Flohrer, et al., The highresolution stereo camera (HRSC) experiment on Mars Express: Instrument aspects and experiment conduct from interplanetary cruise through the nominal mission. Planetary and Space Science, 55, 928-952 (2007)

[5] Malin, M.C., Bell, J.F., Calvin, W., Clancy, R.T., Haberle, R.M., James, P.B., Lee, S.W., Thomas, P.C., Caplinger, M.A., Mars Color Imager (MARCI) on the Mars Climate Orbiter. J. Geophys. Res. 106 (E8), 17651-17672 (2001)

[6] Bell, J.F., et al., Mars Reconnaissance Orbiter Mars Color Imager (MARCI): instrument, description, calibration, and performance. J. Geophys. Res. E 114 (8), E08S92 (2009). https://doi.org/10.1029/2008JE003315.

[7] Sánchez-Lavega, A., Chen-Chen, H., Ordonez-Etxeberria, I., Hueso, R., del Rio-Gaztelurrutia, T., Garro, A., \& Wood, S., Limb clouds and dust on Mars from images obtained by the Visual Monitoring Camera (VMC) onboard Mars Express. Icarus, 299, 194-205 (2018)

[8] Hernández $\square$ Bernal, J., Sánchez $\square$ Lavega, A., del Río $\square$ Gaztelurrutia, T., Hueso, R., Cardesín $\square$ Moinelo, A., Ravanis, E. M., Tivov, D., \& Wood, S., The 2018 Martian Global Dust Storm over the South Polar Region studied with MEx/VMC. Geophys. Research Lett., 46, 10330-10337 (2019)

[9] ISIS. Integrated Software for Imagers and Spectrometers (accessed 2021). https://isis.astrogeology.usgs.gov/ 